Article

\title{
Phytotoxic and Antifungal Metabolites from Curvularia crepinii QTYC-1 Isolated from the Gut of Pantala flavescens
}

\author{
Caiping Yin ${ }^{1,2,+}$, Liping Jin ${ }^{2,+}$, Feifei Sun ${ }^{2}$, Xiao $\mathrm{Xu}^{2}$, Mingwei Shao ${ }^{2}$ and Yinglao Zhang $1,2, * \mathbb{B}$ \\ 1 School of Life Sciences, Anhui Agricultural University, Hefei 230036, China; yinglaozhang@aliyun.com \\ 2 College of Chemistry and Life Sciences, Zhejiang Normal University, Jinhua 321004, China; \\ goldlp900906@163.com (L.J.); desunfeifei@163.com (F.S.); xuxiaoxiao0602@163.com (X.X.); \\ jianting880720@126.com (M.S.) \\ * Correspondence: zhangyl@ahau.edu.cn; Tel.: +86-551-6578-6129 \\ + These authors contributed equally to this work.
}

Received: 29 March 2018; Accepted: 13 April 2018; Published: 19 April 2018

\begin{abstract}
Four metabolites (1-4), including a new macrolide, $O$-demethylated-zeaenol (2), and three known compounds, zeaenol (1), adenosine (3), and ergosta-5,7,22-trien-3b-ol (4) were isolated and purified from Curvularia crepinii QTYC-1, a fungus residing in the gut of Pantala flavescens. The structures of isolated compounds were identified on the basis of extensive spectroscopic analysis and by comparison of the corresponding data with those reported in the literature previously. The new compound $\mathbf{2}$ showed good phytotoxic activity against Echinochloa crusgalli with an $\mathrm{IC}_{50}$ value of less than $5 \mu \mathrm{g} / \mathrm{mL}$, which was comparable to that of positive 2,4-dichlorophenoxyacetic acid (2,4-D). Compound 1 exhibited moderate herbicidal activity against $E$. crusgalli with an $\mathrm{IC}_{50}$ value of $28.8 \mu \mathrm{g} / \mathrm{mL}$. Furthermore, the new metabolite 2 was found to possess moderate antifungal activity against Valsa mali at the concentration of $100 \mu \mathrm{g} / \mathrm{mL}$, with the inhibition rate of $50 \%$. These results suggest that the new macrolide $\mathbf{2}$ and the known compound $\mathbf{1}$ have potential to be used as biocontrol agents in agriculture.
\end{abstract}

Keywords: Curvularia crepinii; Pantala flavescens; phytotoxic activity; antifungal activity; macrolide; natural product

\section{Introduction}

Both weeds and plant fungal diseases have always been thought as big agricultural and environmental problems [1-3]. Organic synthetic herbicides and fungicides are widely used to control these issues. However, these synthetic chemicals may create serious problems to human health and lead to environmental pollution due to their slow biodegradation. Moreover, concerns of toxicity makes it necessary to discover more effective and safer herbicides and fungicides. The study of microbial secondary metabolites offers useful evidence in the investigation of new types of natural herbicides and fungicides that could be less harmful and more specific than the synthetic chemical agents currently used in agriculture [4-6]. Therefore, microbial natural products have attracted attention as reliable alternatives to synthetic agricultural chemicals [7].

Insect gut microorganisms constitute a rich and complex microbial population, and have gained attention as a resource of new bioactive metabolites [8-10]. In the proceeding of our ongoing efforts to find new natural herbicides and fungicides from insect gut microbes [11], we found that the extract from the solid fermentation of the fungal strain Curvularia crepinii QTYC-1, isolated from the gut of Pantala flavescens, exhibited potent phytotoxic activities against the radical growth of Echinochloa crusgalli and Amaranthus retroflexus, as well as antifungal activity against plant pathogens. 
Further examination of the crude extract led to the isolation of one new macrolide along with three known compounds. Here, we reported the details of the isolation, structure characterization, and bioactivities of these metabolites.

\section{Results and Discussion}

\subsection{Identification of the Fungus}

Colonies of QTYC-1 on malt-extract agar (MEA) grew quickly at $28^{\circ} \mathrm{C}$, covering the whole plate $(9 \mathrm{~cm}$ in diameter) in 10 days. The morphological features of the strain QTYC-1 were similar to those of Curvularia sp [2], which produced four-celled ellipsoidal conidia. Phylogenetic taxonomy with the sequence alignment of ITS (Internal Transcribed Spacer) rDNA of the fungus was achieved with MEGA 5.0 software (http:/ / www.megasoftware.net). The phylogenetic tree (Figure 1) indicated that the title fungus was closely related to Curvularia crepinii (KU877619), with the ITS sequence similarity of $100 \%$. Combined with the morphological characteristics, the fungus was identified as C. crepinii.

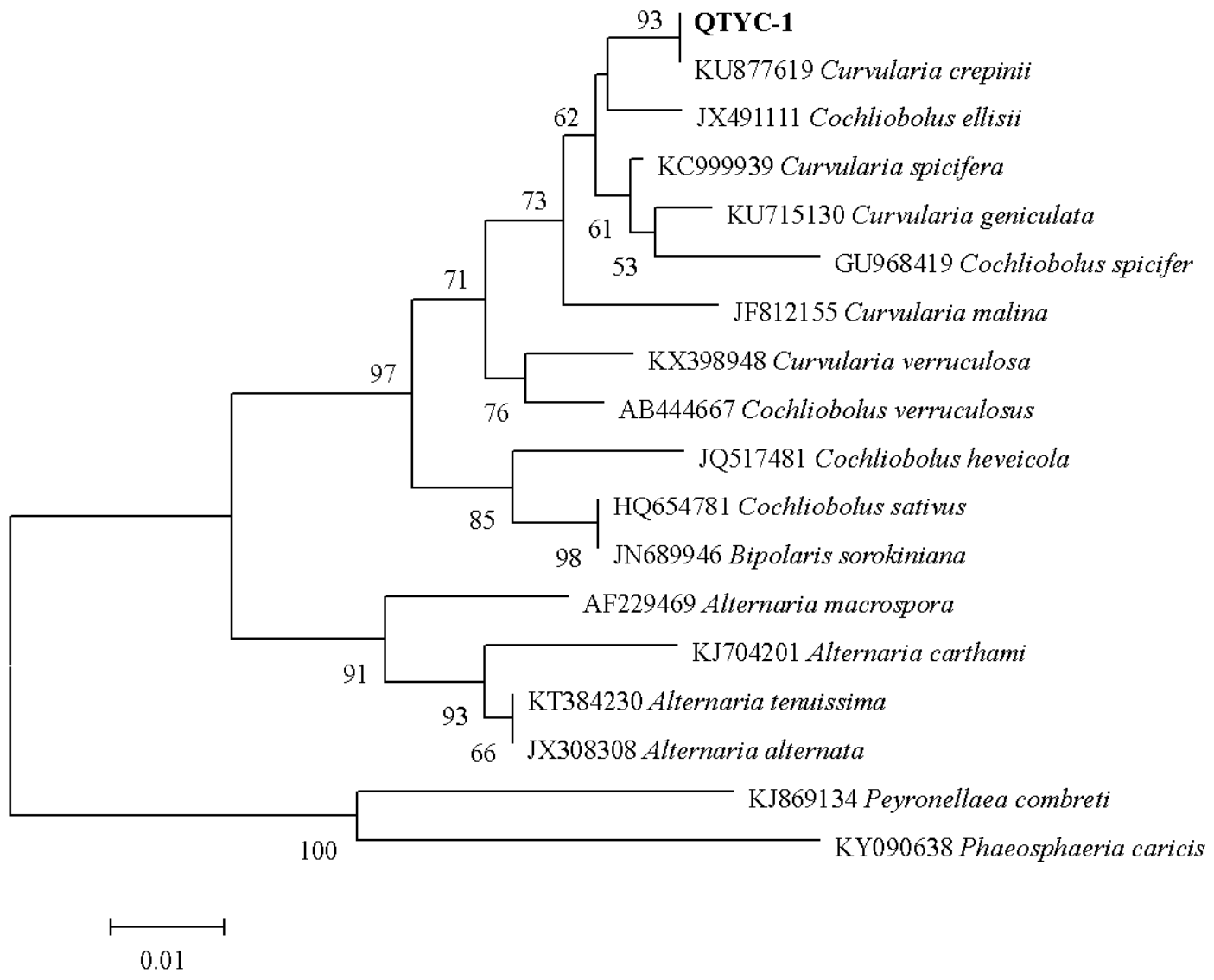

Figure 1. The phylogenetic tree of QTYC-1 based on the 5.8S rDNA sequences.

\subsection{Identification of Active Compounds}

Bioassay-guided fractionation of the constituents in the ethyl acetate extract of $C$. crepinii QTYC-1 yielded a novel macrolide derivate $\mathbf{2}$ and three known active metabolites (Figure 2). 


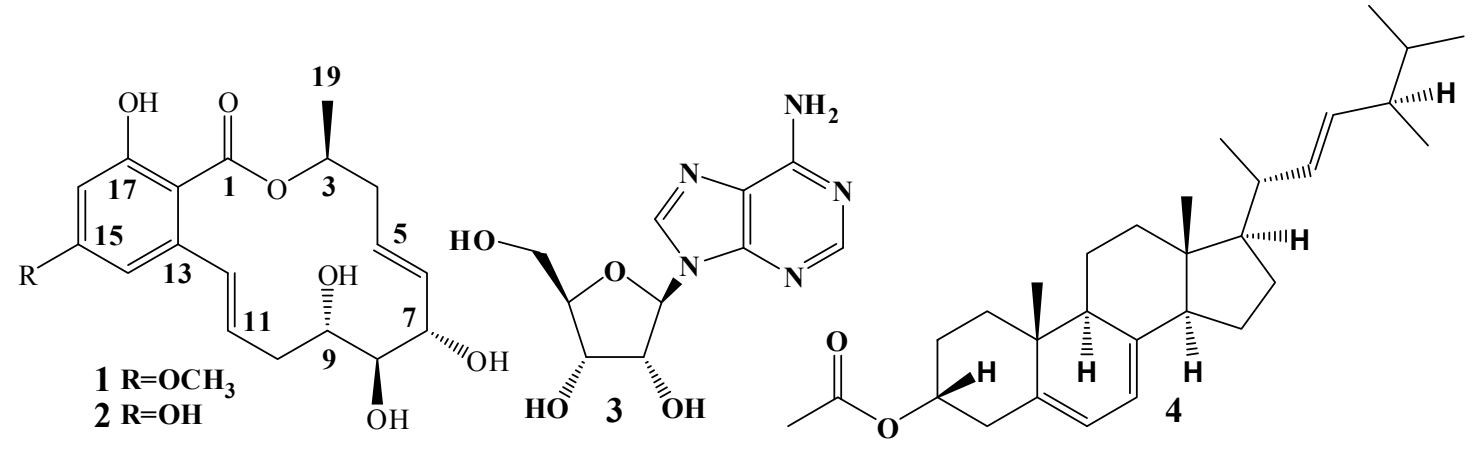

Figure 2. Chemical structures of secondary metabolites 1-4 of C. crepinii QTYC-1.

Compound 2 was obtained as a white powder. Its molecular formula $\mathrm{C}_{18} \mathrm{H}_{22} \mathrm{O}_{7}$ was deduced from ESI-MS $m / z 373[\mathrm{M}+\mathrm{Na}]^{+}, 701[2 \mathrm{M}+\mathrm{H}]^{+}$, which was consistent with the ${ }^{1} \mathrm{H}-\mathrm{NMR}$ and ${ }^{13} \mathrm{C}-\mathrm{NMR}$ data (Supplementary Materials, Figures S1-S6). The ${ }^{1} \mathrm{H}-\mathrm{NMR}$ (Table 1) of 2 indicated the presence of 1,3-disubstituted benzene ring $\left(\delta_{\mathrm{H}} 6.45, J=2.4 \mathrm{~Hz} ; \delta_{\mathrm{H}} 6.27, J=2.4 \mathrm{~Hz}\right)$, one methyl $\left(\delta_{\mathrm{H}} 1.47\right)$, and two methylenes. Five proton signals at $\delta_{\mathrm{H}} 3.93,3.96,3.80,9.37$, and 11.89 were assigned to hydroxy groups because no HMQC correlation was observed. The ${ }^{1} \mathrm{H}$ - and ${ }^{13} \mathrm{C}-\mathrm{NMR}$ data were similar to those of zeaenol (1), except the $O$-demethylation at position 15 in $\mathbf{1}$ appeared to be $\mathrm{OCH}_{3}$ [12], which corresponded to the decrease in molecular weight of 2 by 14 amu compared to 1 . This was further confirmed by the HMBC correlation of HO-15 to C-14 $\left(\delta_{C} 108.6\right), C-15\left(\delta_{C} 163.4\right), C-16\left(\delta_{C} 102.6\right)$. Further confirmation was achieved by the HMBC correlation of H-14 to C-12 $\left(\delta_{C} 133.5\right), C-15, C-16, C-18$ $\left(\delta_{\mathrm{C}} 103.8\right) ; \mathrm{H}-16$ to $\mathrm{C}-14, \mathrm{C}-18 ; \mathrm{H}-19$ to $\mathrm{C}-3\left(\delta_{\mathrm{C}} 72.7\right), \mathrm{C}-4\left(\delta_{\mathrm{C}} 38.0\right) ; \mathrm{H}-3$ to $\mathrm{C}-1\left(\delta_{\mathrm{C}} 172.4\right), \mathrm{C}-5\left(\delta_{\mathrm{C}} 127.9\right)$; H-4a to C-6 $\left(\delta_{C} 133.2\right), C-19\left(\delta_{C} 19.5\right) ; \mathrm{H}-5$ to C-3, C-7 $\left(\delta_{C} 73.7\right) ; \mathrm{H}-6$ to C-4; H-7 to C-5, C-8 $\left(\delta_{C} 78.9\right)$; $\mathrm{H}-10 \mathrm{~b}$ to C-8, C-12; H-11 to C-9 $\left(\delta_{\mathrm{C}} 74.2\right), \mathrm{C}-13\left(\delta_{\mathrm{C}} 144.8\right) ; \mathrm{H}-12$ to C-10 $\left(\delta_{\mathrm{C}} 37.1\right), \mathrm{C}-13, \mathrm{C}-14, \mathrm{C}-18 ; \mathrm{HO}-17$ to $\mathrm{C}-16, \mathrm{C}-18$. Thus, the structure of $\mathbf{2}$ was an $\mathrm{O}$-demethylated derivative of $\mathbf{1}$ and was determined as $\left(3 S^{*}, 5 E, 7 S^{*}, 8 S^{*}, 9 S^{*}, 11 E\right)-7,8,9,15,17$-pentahydroxy-3-methyl-3,4,7,8,9,10-hexahydro-1H-benzo[c][1] oxacyclotetradecin-1-one. The planar structure of compound 2 has been described previously as an intermediate in the synthesis of derivative 1 [13]. However, it had not been described from nature and the relative configuration of $\mathrm{C}-8$ in $\mathbf{2}$ has not been previously assigned.

Table 1. ${ }^{1} \mathrm{H}-\mathrm{NMR}$ and ${ }^{13} \mathrm{C}-\mathrm{NMR}$ data of compound 2 in acetone- $d_{6}$.

\begin{tabular}{ccc}
\hline Position & $\delta_{\mathbf{H}}$, Mult. $(\boldsymbol{J}$ in Hz) & $\boldsymbol{\delta}_{\mathbf{C}}$ \\
\hline 1 & & 172.4 \\
2 & & \\
3 & $5.32, \mathrm{~m}$ & 72.7 \\
$4 \mathrm{a}$ & $2.54, \mathrm{~m}$ & 38.0 \\
$4 \mathrm{~b}$ & & \\
5 & $5.99, \mathrm{~m}$ & 127.9 \\
6 & $5.70, \mathrm{dd}(15.4,7.3)$ & 133.2 \\
7 & $4.15, \mathrm{t}(7.3,7.6)$ & 73.7 \\
8 & $3.50, \mathrm{~d}(7.6)$ & 78.9 \\
9 & $3.78, \mathrm{~m}$ & 74.2 \\
$10 \mathrm{a}$ & $2.33, \mathrm{~s}$ & 37.1 \\
$10 \mathrm{~b}$ & $2.45, \mathrm{~m}$ & \\
11 & $5.99, \mathrm{~m}$ & 131.4 \\
12 & $7.15, \mathrm{~d}(15.6)$ & 133.5 \\
13 & & 144.8 \\
14 & $6.45, \mathrm{~d}(2.4)$ & 108.6 \\
15 & & 163.4 \\
16 & $6.27, \mathrm{~d}(2.4)$ & 102.6 \\
\hline
\end{tabular}


Table 1. Cont.

\begin{tabular}{ccc}
\hline Position & $\boldsymbol{\delta}_{\mathbf{H}}$, Mult. $(\boldsymbol{J}$ in Hz) & $\delta_{\mathbf{C}}$ \\
\hline 17 & & 166.3 \\
18 & & 103.8 \\
19 & $1.47, \mathrm{~d}(6.2)$ & 19.5 \\
$7-\mathrm{OH}$ & $3.93, \mathrm{~d}(2.3)$ & \\
$8-\mathrm{OH}$ & $3.96, \mathrm{~d}(3.0)$ & \\
$9-\mathrm{OH}$ & $3.80, \mathrm{~s}$ & \\
$15-\mathrm{OH}$ & $9.37, \mathrm{~s}$ & \\
$17-\mathrm{OH}$ & $11.89, \mathrm{~s}$ & \\
\hline
\end{tabular}

The other secondary metabolites were identified as zeaenol (1) [12], adenosine (3) [14], and ergosta5,7,22-trien-3b-ol (4) [15], by comparing their MS and NMR spectroscopic data with those reported in the literatures.

The genus of Curvularia species was well-known to produce a variety of secondary metabolites. Previous investigations led to the isolation of several compounds such as antimicrobial curvulone A-B and curvularides A-E [16,17], motility inhibitor murranofuran A [18], cytotoxic pentanorlanostane, and pyrenocine $J[19,20]$. However, to the best of our knowledge, this is the first report of the new macrolide 2 isolated from the title strain C. crepinii QTYC-1, a fungus residing in the P. flavescens gut.

\subsection{Phytotoxic Activity of the Bioactive Metabolites}

Compounds 1-4 were assayed for their ability to inhibit radicle growth of E. crusgalli and A. retroflexus using a Petri dish bioassay. The result (Figure 3) showed that compounds $\mathbf{1}$ and $\mathbf{2}$ were very active in reducing radicle growth of E. crusgalli with inhibition rates of $85.5 \%$ and $85.6 \%$, respectively, which was comparable to the activity of positive 2,4-dichlorophenoxyacetic acid (2,4-D) with an inhibition rate of $97.5 \%$ under the concentration of $100 \mu \mathrm{g} / \mathrm{mL}$. Compounds 1-3 showed potent phytotoxic activity against $A$. retroflexus with inhibition rates of $66 \sim 76 \%$ at the concentration of $100 \mu \mathrm{g} / \mathrm{mL}$. However, compound 4 showed weak inhibitory effect against $A$. retroflexus and no obvious inhibitory effects were displayed by compounds 3 and $\mathbf{4}$ against $E$. crusgalli in this bioassay.

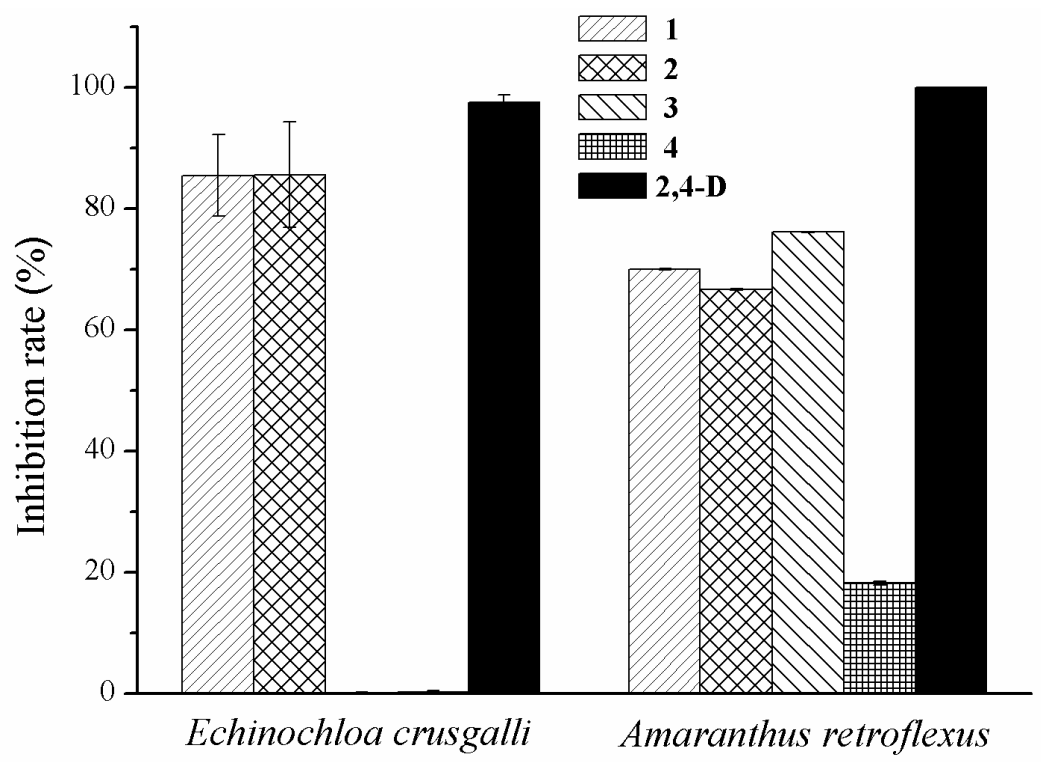

Figure 3. The phytotoxic effects of compounds 1-4 on radicle growth of E. crusgalli and A. retroflexus.

Compounds 1 and $\mathbf{2}$ were further tested to elucidate their phytotoxic activity at different concentrations against E. crusgalli, compared to 2,4-D co-assayed as a positive reference. The result (Figure 4) showed that 
compounds 1 and 2 exhibited phytotoxic activity in a dose-dependent manner (5-50 $\mu \mathrm{g} / \mathrm{mL})$. Furthermore, the new compound 2 exhibited higher phytotoxic activity than compound $\mathbf{1}$ at the same concentration. The $50 \%$ inhibitory concentration ( $\mathrm{IC}_{50}$ value) of the new compound 2 was less than $5 \mu \mathrm{g} / \mathrm{mL}$, which was comparable to that of positive 2,4-D. Compound 1 exhibited moderate phytotoxic activity against E. crusgalli with an $\mathrm{IC}_{50}$ value of $28.8 \mu \mathrm{g} / \mathrm{mL}$.

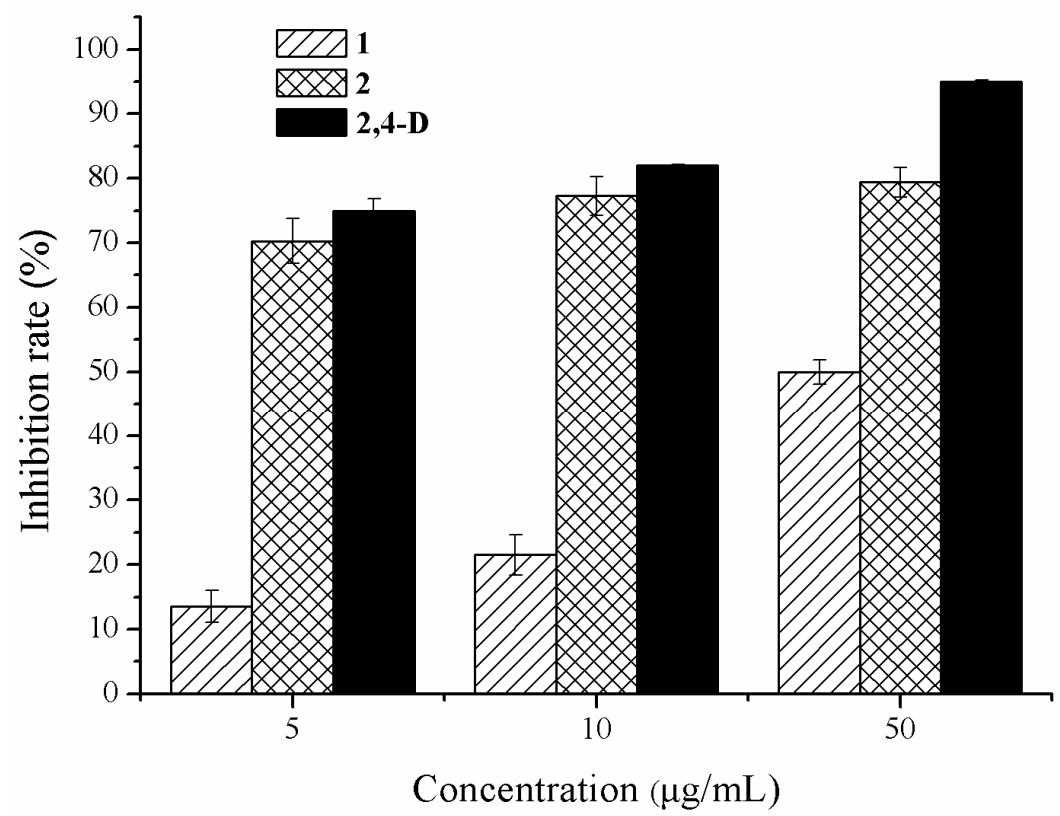

Figure 4. The phytotoxic effects of compounds 1 and 2 with different concentrations on radicle growth of E. crusgalli.

\subsection{In Vitro Effect on Mycelial Growth of Phytopathogenic Fungi}

The effects of metabolites 1-4 against the mycelial growth of five phytopathogenic fungi were evaluated in vitro under the concentration of $100 \mu \mathrm{g} / \mathrm{mL}$ (Table 2). The results showed that metabolite 2 possessed moderate antifungal activity against Valsa mali with an inhibition rate of $50 \%$ when compared with that of positive cycloheximide. However, it weakly inhibited the growth of Gibberella sanbinetti, Alternaria solani, and Fusarium oxysporum f.sp. mornordicae with an inhibition rate of less than $45 \%$. In general, compounds 1, 3 and 4 exhibited weak activities against all tested phytopathogenic fungi with inhibition rates of less than $42 \%$.

Table 2. Inhibition rate of the compounds of QTYC-1 against phytopathogenic fungi (in \%) ${ }^{\mathrm{a}}$.

\begin{tabular}{cccccc}
\hline Phytopathogens & $\mathbf{1}$ & $\mathbf{2}$ & $\mathbf{3}$ & $\mathbf{4}$ & Cycloheximide $^{\mathbf{b}}$ \\
\hline V. mali & $30.4 \pm 0.6$ & $50.0 \pm 0.6$ & NI & $28.9 \pm 0.3$ & $100 \pm 0.0$ \\
D. gregaria & NI & NI & NI & NI & $99.7 \pm 1.6$ \\
G. sanbinetti & $29.5 \pm 0.1$ & $30.4 \pm 0.1$ & $28.4 \pm 0.1$ & NI & $99.0 \pm 0.3$ \\
A. solani & $20.1 \pm 0.1$ & $35.2 \pm 0.1$ & $4.4 \pm 0.1$ & $16.4 \pm 0.1$ & $98.2 \pm 2.7$ \\
F. oxysporum f.sp. mornordicae & $41.1 \pm 0.1$ & $42.2 \pm 0.1$ & $31.3 \pm 0.0$ & $7.5 \pm 0.1$ & $98.7 \pm 0.6$ \\
\hline
\end{tabular}

\footnotetext{
a The concentration of compounds was $100 \mu \mathrm{g} / \mathrm{mL}$; results were presented as the mean \pm standard deviation for
} triplicate experiments. ${ }^{\mathrm{b}}$ Cycloheximide was used as the positive control. $\mathrm{NI}=$ not inhibited.

In summary, we identified one new macrolide, together with three known compounds, from C. crepinii QTYC-1, a fungus residing in the gut of Pantala flavescens. The new macrolide $\mathbf{2}$ and the known compound $\mathbf{1}$ attenuated the radicle growth of E. crusgalli and A. retroflexus, and $\mathbf{2}$ possessed moderate antifungal activity against $V$. mali in vitro. These results suggested that the compounds $\mathbf{1}$ and $\mathbf{2}$ have some potential as agents for weeds or pathogenic fungal control. Further studies will be carried out to better understand the 
mechanism of action associated with phytotoxic and antifungal effects. In addition, the discovery of our study provided additional evidence that the special microorganisms in uninvestigated habitats, just like the title strain, may inspire the discovery of chemical agents with interesting biological activity.

\section{Materials and Methods}

\subsection{Isolation and Identification of Strain QTYC-1}

The strain was isolated based on methods described previously [21]. P. flavescens were collected from the suburb of Jinhua, Zhejiang Province, PR China during the growing season. The insects were brought to the lab and starved for $24 \mathrm{~h}$. The insects were surface-sterilized in $75 \%$ ethanol for $3 \mathrm{~min}$, followed by rinsing in sterilized water three times ( $30 \mathrm{~s}$ each). They were then degutted using sterile forceps. The guts were lightly homogenized, and dilution series $\left(10^{-1}, 10^{-2}, 10^{-3}\right)$ were spread-plated on malt-extract agar (MEA) medium (consisting of $20 \mathrm{~g}$ malt extract, $1 \mathrm{~g}$ peptone, $20 \mathrm{~g}$ sucrose, $20 \mathrm{~g}$ agar in $1 \mathrm{~L}$ of distilled water) containing antibacterial antibiotics (chloramphenicol and penicillin, $100 \mu \mathrm{g} / \mathrm{mL}$ each) to isolate the fungal strain. All of the plates were incubated aerobically in a chamber for $72 \mathrm{~h}$ at $28 \pm 0.5^{\circ} \mathrm{C}$ and any fungal colonies that formed were sub-cultured on new MEA medium to obtain pure cultures. The isolated strain was preserved on MEA slants at $4{ }^{\circ} \mathrm{C}$ until use. The title strain was deposited at the China Center for Type Culture Collection (CCTCC) as CCTCC M 2014308, and identified by comparing the morphological character and ITS sequence to those of standard records.

\subsection{Microbial Fermentation}

Based on the methods detailed elsewhere with trivial changes [22], the fungal strain was cultured on MEA medium at $28 \pm 0.5^{\circ} \mathrm{C}$ for four days. Then, pieces of fresh mycelium were inoculated into 250-mL Erlenmeyer flasks, each containing $100 \mathrm{~mL}$ of malt-extract (ME) liquid medium. After three days of incubation at $28 \pm 0.5^{\circ} \mathrm{C}$ on rotary shakers at $170 \mathrm{rpm}, 10 \mathrm{~mL}$ cultural liquid was transferred as a seed into 1-L Erlenmeyer flasks, each containing $160 \mathrm{~g}$ of rice and $200 \mathrm{~mL}$ distilled $\mathrm{H}_{2} \mathrm{O}$, and incubated at $28 \pm 0.5^{\circ} \mathrm{C}$ for 40 days.

\subsection{Isolation and Characterization of Secondary Metabolites}

The total solid fermentation product in 40 Erlenmeyer flasks was extracted with ethyl acetate $(4 \times 10 \mathrm{~L})$ at room temperature. The solvent was then evaporated in vacuo to afford a crude extract $(50.1 \mathrm{~g})$. The extract was subjected to chromatography over a silica-gel column eluting with a stepwise gradient of $\mathrm{CH}_{2} \mathrm{Cl}_{2} / \mathrm{MeOH}(100: 0-100: 8, v / v)$ to give five fractions (Fr-1 to Fr-5). Fr-1 was further chromatographed over silica gel $\left(\mathrm{CH}_{2} \mathrm{Cl}_{2} / \mathrm{MeOH}, 100: 0-100: 2\right)$ to give four sub-fractions (R1-R4). Compound $4(6.0 \mathrm{mg})$ was crystallized from the $\mathrm{MeOH}$ solution of sub-fraction R2. Fr-3 $\left(\mathrm{CH}_{2} \mathrm{Cl}_{2} / \mathrm{MeOH}, 100: 2\right)$ was repeatedly purified on silica gel $\left(\mathrm{CH}_{2} \mathrm{Cl}_{2} / \mathrm{MeOH}, 100: 1-100: 2\right)$ to yield compounds 1 (100.2 mg) and 2 (7.6 mg). Fr-5 $\left(\mathrm{CH}_{2} \mathrm{Cl}_{2} / \mathrm{MeOH}, 100: 8\right)$ was loaded onto a Sephadex LH-20 column $(\mathrm{MeOH})$ to give compound $3(5.0 \mathrm{mg})$.

Structural identifications of the secondary metabolites were made according to the spectroscopic analysis. The electrospray ionization mass spectrometry (ESI-MS) spectra were collected on a Time-of-Flight Mass Spectrometer G6230AA (Agilent Technologies, Santa Clara, CA, USA). ${ }^{1} \mathrm{H}$ nuclear magnetic resonance (NMR), ${ }^{13} \mathrm{C}-\mathrm{NMR}$ and distortionless enhancement by polarization transfer (DEPT) spectra were acquired on a Bruker AVANCE-600 (Bruker, Fällanden, Switzerland), and chemical shifts were obtained in $\delta$ (ppm) by referring to the tetramethylsilane (TMS) and solvent signals as internal standards. HMQC and HMBC experiments were optimized for 145.0 and $8.0 \mathrm{~Hz}$, respectively. 


\subsection{Phytogrowth Inhibitory Bioassay of Metabolites}

The phytotoxic effects of compounds 1-4 were evaluated on the radicle growth of E. crusgalli and $A$. retroflexus according to the Petri dish bioassay [21]. Briefly, seeds were firstly surface-sterilized with sodium hypochlorite $(1 \%)$ and washed with sterile distilled water before germination. Different concentrations of compounds 1-4 were prepared with acetone. A 5.0-mL sample solution was added to 9 -cm diameter Petri dishes on filter paper disks. To avoid the toxic effect of solvents, filter papers were placed in a cabinet to evaporate the solvent. Subsequently, $5.0 \mathrm{~mL}$ of distilled water was added to each Petri dish. Then, 30 pre-germinated seeds were placed in the Petri dishes. 2,4-dichlorophenoxy acetic acid (2,4-D) was used as the positive reference. Dishes were then kept in an incubator at $25^{\circ} \mathrm{C}$ under dark conditions. After two days, root length was checked and compared with the untreated control. The inhibition percent was calculated using the formula as follows:

$$
\text { Inhibition }(\%)=\left(\mathrm{L}_{\text {control }}-\mathrm{L}_{\text {treatment }}\right) / \mathrm{L}_{\text {control }} \times 100
$$

where $\mathrm{L}_{\text {control }}=$ radicle length of the seedlings in the control and $\mathrm{L}_{\text {treatment }}=$ radicle length of the seedlings treated.

\subsection{In Vitro Effect on Mycelial Growth of Phytopathogenic Fungi}

Antifungal bioactivities against phytopathogenic fungi were carried out by the mycelium growth rate method as described previously with slight changes [23,24]. Purified metabolites were dissolved in an aqueous solution (composed of 4\% Tween-80 and 1\% DMSO). Solutions of purified chemicals were mixed with MEA in a Petri dish $(9 \mathrm{~cm}$ in diameter). Cycloheximide was used as the positive control. After inoculation of the fungal mycelia onto the center of the solid medium, the dishes were incubated in the dark at $28 \pm 0.5^{\circ} \mathrm{C}$. When the fungal mycelium reached the edges of the control dishes, the antifungal activities were calculated. The formula for counting the percentage of growth inhibition is as follows:

$$
\text { Inhibition }(\%)=(1-\mathrm{Da} / \mathrm{Db}) \times 100
$$

where $\mathrm{Da}$ is the diameter of the growth zone in the experimental dish $(\mathrm{mm})$ and $\mathrm{Db}$ is the diameter of the growth zone in the control dish (mm).

\subsection{Statistical Analysis}

All experiments were performed in triplicate, and data are shown as mean values \pm standard deviation. A least significant difference (LSD) test with a confidence interval of $95 \%$ was used to compare the means.

Supplementary Materials: Supplementary materials can be accessed online. Figure S1: ${ }^{1} \mathrm{H}-\mathrm{NMR}$ spectrum $(600 \mathrm{MHz})$ of the compound 2 in Acetone- $d_{6}$. Figure S2: ${ }^{13} \mathrm{C}-\mathrm{NMR}$ spectrum $(150 \mathrm{MHz})$ of compound 2 in Acetone- $d_{6}$. Figure S3: DEPT 135 spectrum of compound 2 in Acetone- $d_{6}$. Figure S4: ${ }^{1} \mathrm{H}_{-}{ }^{1} \mathrm{H}$ COSY spectrum of compound 2 in Acetone- $d_{6}$. Figure S5: HMQC spectrum of compound 2 in Acetone- $d_{6}$. Figure S6: HMBC spectrum of compound 2 in Acetone- $d_{6}$.

Acknowledgments: This work was co-financed by the National Natural Science Foundation of China (NSFC) (31770007) and the Zhejiang Provincial Natural Science Foundation of China (LY17C010002).

Author Contributions: C.Y. contributed to screening, fermentation, structure elucidation, antifungal assay, and manuscript writing; L.J. contributed to the isolation of compounds, structure elucidation, phytotoxic assay, and manuscript preparation; F.S. performed the antifungal assay; X.X. contributed to the screening experiment; M.S. contributed to the selection of the producer strain; Y.Z. guided the experiments and microbial identification, and edited the manuscript.

Conflicts of Interest: The authors declare no conflict of interest. 


\section{References}

1. Shi, D.; An, R.; Zhang, W.; Zhang, G.; Yu, Z. Stilbene derivatives from Photorhabdus temperata SN259 and their antifungal activities against phytopathogenic fungi. J. Agric. Food Chem. 2017, 65, 60-65. [CrossRef] [PubMed]

2. Zhang, Y.L.; Kong, L.C.; Jiang, D.H.; Yin, C.P.; Cai, Q.M.; Chen, Q.; Zheng, J.Y. Phytotoxic and antifungal metabolites from Curvularia sp. FH01 isolated from the gut of Atractomorpha sinensis. Bioresource Technol. 2011, 102, 3575-3577. [CrossRef] [PubMed]

3. Lu, Y.H.; Jin, L.P.; Kong, L.C.; Zhang, Y.L. Phytotoxic, antifungal and immunosuppressive metabolites from Aspergillus terreus QT122 isolated from the gut of dragonfly. Curr. Microbiol. 2017, 74, 84-89. [CrossRef] [PubMed]

4. Wang, J.; He, W.; Huang, X.; Tian, X.; Liao, S.; Yang, B.; Wang, F.; Zhou, X.; Liu, Y. Antifungal new oxepine-containing alkaloids and xanthones from the deep-sea-derived fungus Aspergillus versicolor SCSIO 05879. J. Agric. Food Chem. 2016, 64, 2910-2916. [CrossRef] [PubMed]

5. García-Méndez, M.C.; Macías-Ruvalcaba, N.A.; Lappe-Oliveras, P.; Hernández-Ortega, S.; Macías-Rubalcava, M.L. Phytotoxic potential of secondary metabolites and semisynthetic compounds from endophytic fungus Xylaria feejeensis Strain SM3e-1b isolated from Sapium macrocarpum. J. Agric. Food Chem. 2016, 64, 4255-4263. [CrossRef] [PubMed]

6. Bi, Y.; Yu, Z. Diterpenoids from Streptomyces sp. SN194 and their antifungal activity against Botrytis cinerea. J. Agric. Food Chem. 2016, 64, 8525-8529. [CrossRef] [PubMed]

7. Masi, M.; Meyer, S.; Clement, S.; Pescitelli, G.; Cimmino, A.; Cristofaro, M.; Evidente, A. Chloromonilinic acids $\mathrm{C}$ and $\mathrm{D}$, phytotoxic tetrasubstituted 3-chromanonacrylic acids isolated from Cochliobolus australiensis with potential herbicidal activity against buffelgrass (Cenchrus ciliaris). J. Nat. Prod. 2017, 80, 2771-2777. [CrossRef] [PubMed]

8. Zhang, Y.L.; Ge, H.M.; Zhao, W.; Dong, H.; Xu, Q.; Li, S.H.; Li, J.; Zhang, J.; Song, Y.C.; Tan, R.X. Unprecedented immunosuppressive polyketides from Daldinia eschscholzii, a mantis associated fungus. Angew. Chem. Int. Ed. 2008, 120, 5907-5910. [CrossRef]

9. Wang, G.; Fan, J.Y.; Zhang, W.J.; Hua, C.P.; Chen, C.J.; Yan, W.; Ge, H.M.; Jiao, R.H.; Tan, R.X. Polyketides from mantis-associated fungus Daldinia eschscholzii IFB-TL01. Chem. Biodivers. 2015, 12, 1349-1355. [CrossRef] [PubMed]

10. Zhang, Y.L.; Zhang, J.; Jiang, N.; Lu, Y.H.; Wang, L.; Xu, S.H.; Wang, W.; Zhang, G.F.; Xu, Q.; Ge, H.M.; et al. Immunosuppressive polyketides from the mantis-associated Daldinia eschscholzii. J. Am. Chem. Soc. 2011, 133, 5931-5940. [CrossRef] [PubMed]

11. Shao, M.W.; Kong, L.C.; Jiang, D.H.; Zhang, Y.L. Phytotoxic and antimicrobial metabolites from Paraphaeosphaeria sp. QTYC11 isolated from the gut of Pantala flavescens Larvae. Rec. Nat. Prod. 2016, 10, 326-331.

12. Sugawara, F.; Kim, K.W.; Kobayashi, K.; Uzawa, J.; Yoshida, S.; Murofushi, N.; Takahashi, N.; Strobel, G.A. Zearalenone derivatives produced by the fungus Drechslera Portulacae. Phytochemistry 1992, 31, 1987-1990. [CrossRef]

13. Dakas, P.Y.; Jogireddy, R.; Valot, G.; Barluenga, S.; Winssinger, N. Divergent syntheses of resorcylic acid lactones: L-783277, LL-Z1640-2, and hypothemycin. Chem. Eur. J. 2009, 15, 11498-11506. [CrossRef] [PubMed]

14. Ciuffreda, P.; Casati, S.; Manzocchi, A. Complete ${ }^{1} \mathrm{H}$ and ${ }^{13} \mathrm{C}$ NMR spectral assignment of $\alpha$-and $\beta$-adenosine, 2'-deoxyadenosine and their acetate derivatives. Magn. Reson. Chem. 2007, 45, 781-784. [CrossRef] [PubMed]

15. Wang, F.; Tan, J.W.; Liu, J.K. Vibratilicin: A novel compound from the Basidiomycete Cortinarius vibratilis. Helv. Chim. Acta 2004, 87, 1912-1915. [CrossRef]

16. Chomcheon, P.; Wiyakrutta, S.; Aree, T.; Sriubolmas, N.; Ngamrojanavanich, N.; Mahidol, C.; Ruchirawat, S.; Kittakoop, P. Curvularides A-E: Antifungal hybrid peptide-polyketides from the endophytic fungus Curvularia geniculate. Chem. Eur. J. 2010, 16, 11178-11185. [CrossRef] [PubMed]

17. Dai, J.; Krohn, K.; Flörke, U.; Pescitelli, G.; Kerti, G.; Papp, T.; Kövér, K.E.; Bényei, A.C.; Draeger, S.; Schulz, B.; et al. Curvularin-type metabolites from the fungus Curvularia sp. isolated from a marine alga. Eur. J. Org. Chem. 2010, 36, 6928-6937. [CrossRef] 
18. Mondol, M.A.M.; Farthouse, J.; Islam, M.T.; Schüffler, A.; Laatsch, H. Metabolites from the endophytic fungus Curvularia sp. M12 act as motility inhibitors against Phytophthora capsici zoospores. J. Nat. Prod. 2017, 80, 347-355. [CrossRef] [PubMed]

19. Xue, C.Y.; Li, J.S.; Qi, H.; Xi, F.Y.; Xiang, W.S.; Wang, J.D.; Wang, X.J. Two new pentanorlanostane metabolites from a soil fungus Curvularia borreriae strain HS-FG-237. J. Antibiot. 2013, 66, 735-737. [CrossRef] [PubMed]

20. Zhang, H.; Mao, L.L.; Qian, P.T.; Shan, W.G.; Wang, J.D.; Bai, H. Two new metabolites from a soil fungus Curvularia affinis strain HS-FG-196. J. Asian Nat. Prod. Res. 2012, 14, 1078-1083. [CrossRef] [PubMed]

21. Li, S.; Shao, M.W.; Lu, Y.H.; Kong, L.C.; Jiang, D.H.; Zhang, Y.L. Phytotoxic and antibacterial metabolites from Fusarium proliferatum ZS07 isolated from the gut of long-horned grasshoppers. J. Agric. Food Chem. 2014, 62, 8997-9001. [CrossRef] [PubMed]

22. Ding, G.; Wang, H.; Li, L.; Song, B.; Chen, H.; Zhang, H.; Liu, X.; Zou, Z. Trichodermone, a spiro-cytochalasan with a tetracyclic nucleus $(7 / 5 / 6 / 5)$ skeleton from the plant endophytic fungus Trichoderma gamsii. J. Nat. Prod. 2014, 77, 164-167. [CrossRef] [PubMed]

23. Lv, P.; Chen, Y.; Zhao, Z.; Shi, T.; Wu, X.; Xue, J.; Li, Q.X.; Hua, R. Design, synthesis, and antifungal activities of 3-acyl thiotetronic acid derivatives: new fatty acid synthase inhibitors. J. Agric. Food Chem. 2018, 66, 1023-1032. [CrossRef] [PubMed]

24. Zhang, Y.L.; Li, S.; Jiang, D.H.; Kong, L.C.; Zhang, P.H.; Xu, J.D. Antifungal activities of metabolites produced by a termite-associated Streptomyces canus BYB02. J. Agric. Food Chem. 2013, 61, 1521-1524. [CrossRef] [PubMed]

Sample Availability: Samples of the compounds are available from the authors.

(C) 2018 by the authors. Licensee MDPI, Basel, Switzerland. This article is an open access article distributed under the terms and conditions of the Creative Commons Attribution (CC BY) license (http:// creativecommons.org/licenses/by/4.0/). 